\title{
The importance of relationships in international collaborations
}

The ability of global partnerships to develop nurse leaders and international workforce capacity more generally, is well documented (Spies et al 2015, Blaney 2012, Lasater et al 2012). Indeed, if created well, Spies et al (2015) acknowledge that the development of such collaboration can foster an attitude of cultural humility and a commitment to global engagement that will enhance education, scholarship, nursing practice and indeed, the profession as a whole. From my own experience, it is not organisations or events that create successful partnerships but relationships and how we approach and engage with our fellow colleagues and this is reinforced by Boland et al (2010). Cultural humility and an attitude of mutual respect, as identified by Spies et al (2015) for me are key to success along with an open and receptive attitude and a belief that everyone can learn from others. In recent years as I have travelled both nationally and internationally, I have found a real sense of belonging with my fellow nurses and, by showing due respect for the individual, does bring us closer together. It allows friendships to develop, open and trusting relationships to be created and ultimately allows a collaboration that can grow. Together, we can effect change.

Very recently I have attended three international collaborations in as many weeks and I have been struck with the immense sense of collegiality of being in a global community of nurses and the energy created was palpable. Two of these were European conferences and the most recent, the Board meeting of Sigma Theta Tau International (Sigma) held in Indianapolis, USA. I have returned from each engagement with a real sense of gain and potential for future collaborations and more sustained and organised relationships. All three experiences illustrated just how individually and quite separately, nurses have embraced the notion of collaboration and its importance to their practice of either education, clinical practice or research.

The first was a European conference which took place in Malta. With a population of 423,000 , Malta is the most densely populated country in the European Union and one of the most densely populated countries in the world (Worldometers 2018). With approximately 1 doctor to every 3 nurses in Malta, there has been little drive to develop advanced clinical nurses, though the existing 29 advanced specialist nurses are beginning to drive change (Ward 2017). Maltese nurses are passionate about learning from others and driving their practice forward (Ward 2018). As was the situation in the UK, Maltese clinical nurses tend to be promoted into education or management rather than retain their specialist clinical skills, so for those keen to remain in practice, the specialist role is certainly appealing though their creation is dictated by others (Ward 2017). Whilst advanced clinical practice in Malta is in its infancy and seems to be highly influenced by government, Ward (2017) recommends a need for nurses to seek opportunities to be involved in policy and influence their professional trajectory, rather than have it defined by others. Collaboration with others will support them in their endeavours.

I believe there are lessons here for us all. Given the small island state of Malta, the visibility of nurses is considerable and the potential to continuously innovate and be creative in their working lives is limited if they fail to extend their reach both nationally and internationally and of course they are well versed in this endeavour. Indeed, their future is dependent on collaboration. 
The second experience was the $4^{\text {th }}$ European Regional conference of Sigma in Cambridge. With almost 300 delegates from 29 different countries, there was a real sense of sharing best practice and a keenness to learn lessons from colleagues from across the globe. The common thread between the two conferences was the theme of how nurses were influencing education, research and professional practice in these times of constant change. Driven by their need to gain evidence of their continuing professional development (CPD) but more importantly, seeking connections with colleagues and 'friends' from across the globe, American nurses seemed to have it sorted. They understood the importance of human relations in any international collaboration and made every effort to reach out. I observed the art of creating and sustaining global collaborations with colleagues I had met some seven years ago and the other side of the world. These colleagues made every effort, not only to attend our conference but to make considerable efforts to re-establish the connection. For those whose English was not their first language, I experienced real cultural humility, as they reached out to connect. For those whose native language was English, they supported those who struggled to engage. The tolerance and respect on both sides was striking. The poster room was always full with delegates scrutinising the numerous colourful posters, each with their meaningful lessons and the break times saw most delegates reaching out to get to know perfect strangers. We each left the conference feeling enriched, not just from the lessons we learned but the friendships we gained and the embryonic collaborations formed.

Finally, I have just returned from a Sigma Board meeting in the United States. With a very large agenda, all members convened, prepared to address the numerous strategic issues facing the society and eager to engage in collaboration to address them. A fairly new Board, formed last November and with only one previous face to face meeting, all members prioritised their commitment to understand each other individually, knowing that understanding the person is key to having the courage to speak out, engage, and learn to challenge existing assumptions. Whatever level in the organisation, we each test out relationships to discern which of them lend themselves to competition or collaboration. Yet we each contribute at least $50 \%$ to creating that relationship.

In conclusion, whilst international workforce capacity does benefit from successful collaborations, they are dependent on positive relationships and a receptive attitude between all parties; and, we share a collective responsibility to contribute to their success. It is people not processes that make them work.

Words: 1001

\section{References}

Blaney, P., (2012) Senior nursing leadership_capacity building at the global level. International Nursing Review. 59 (1), 40-47. http://dx.doi.org/10.1111/j.14667657.2011.00953.x.

Boland, M.G., Kamikawa, C., Inouye, J., Latimer, R.W., Marshall, S., (2010) Partnership to build research capacity. Nurs. Econ. 28, 314-336.

Lasater, K., Upvall, M., Nielsen, A., Prak, M., Ptachcinski, R., 2012. Global partnerships for professional development: a Cambodian exemplar. Journal of Professional Nursing 28 (1), 62-68. http://dx.doi.org/10.1016/..profnurs.2011.10.002. 
Spies, L.A., Gamer, S.L. and Prater, L. (2015) Building global nurse capacity through relationships, education and collaboration. Nurse Education Today, 35, 653-656.

Ward, M.C. (2017) An Exploration of Specialist Nurses in Malta: A Qualitative Study. Unpublished PhD thesis, $5^{\text {th }}$ May, Bournemouth University, England.

Worldometers (2018) Population of Malta. Accessed at http://www.worldometers.info/worldpopulation/malta-population/ on 16.6.18

\section{Professor Elizabeth Rosser}

Bournemouth University

$16^{\text {th }}$ June 2018 